\title{
Sports Involvement, Injury History, and Non-Medical Use of Prescription Opioids Among College Students: An Analysis With a National Sample
}

\author{
Jason A. Ford, PhD (iD, ${ }^{1}$ Corey Pomykacz, MA, ${ }^{1}$ Philip Veliz, PhD, ${ }^{2,3}$ \\ Sean Esteban McCabe, PhD, ${ }^{2,3}$ Carol J. Boyd, PhD ${ }^{2,3,4}$ \\ ${ }^{1}$ Department of Sociology, University of Central Florida, Orlando, Florida \\ ${ }^{2}$ School of Nursing, Health Behavior and Biological Sciences, University of Michigan, Ann Arbor, Michigan \\ ${ }^{3}$ Institute for Research on Women and Gender, University of Michigan, Ann Arbor, Michigan \\ ${ }^{4}$ Department of Psychiatry, Addiction Research Center, University of Michigan, Ann Arbor, Michigan
}

Background and Objectives: The United States is in the midst of a prescription drug epidemic, particularly related to opioids. To more effectively deal with the devastating outcomes associated with nonmedical use of prescription opioids (NUPO), research is needed to identify populations at increased risk. The current research builds on a small number of studies that have shown that adolescents involved in competitive sports are more likely to report NUPO. Specifically, we examine the relationship between athlete status, injury history, and NUPO among college students.

Methods: Using data from the National College Health Assessment (NCHA II from 2008 to 2011), we estimated several logistic regression models to examine the individual, and combined, effects of sex, athlete status, and injury history on NUPO.

Results: In the NCHA II $8.3 \%$ of students reported NUPO, $8.0 \%$ identified as a varsity athlete, and $17.4 \%$ reported an injury. Looking at factors individually, having an injury, being a varsity athlete, and being male were all significantly associated with NUPO. By combining these factors together we were able to determine that male athletes, athletes with injuries, and male athletes with injuries were at the greatest risk for NUPO, after controlling for relevant covariates.

Discussion and Conclusions: To create effective prevention and intervention programs that target the health and wellness of college students, it is important to understand which groups of students are most likely to report NUPO.

Scientific Significance: This study advances our understanding of the relationship between sports involvement and NUPO. (Am J Addict 2018;27:15-22).

Received August 17, 2017; revised November 27, 2017; accepted November 29, 2017.

Address correspondence to Jason A. Ford, Department of Sociology, University of Central Florida, Orlando, FL 32816.

E-mail: jason.ford@ucf.edu

\section{INTRODUCTION}

Sports involvement is nearly ubiquitous for children and adolescents in the United States. Based on data from the National Collegiate Athletic Association, in 2016 there were nearly 8 million high school students and 500,000 college students involved in official athletic programs. ${ }^{1}$ Both conventional wisdom and empirical research identify sports involvement as being linked to a number of prosocial outcomes. Research among high school and college students shows that students involved in sports are less likely to be involved in delinquent/criminal behavior, ${ }^{2-4}$ have lower levels of marijuana and other illicit drug use, ${ }^{5,6}$ have better physical and mental health, ${ }^{7,8}$ and better academic outcomes. ${ }^{9}$ This protective effect is, in part, due to the strong social bonds to parents and other pro-social adults, as well as a commitment to conventional activities and future outcomes that is facilitated by sports involvement. ${ }^{10}$

That being said, some research has found sports involvement to be a risk factor for certain types of risky or deviant behaviors. For example, research shows that both high school and college students involved in athletics are at increased risk for alcohol use and binge drinking. ${ }^{6,11,12}$ This relationship varies based on gender, the type of sport, and level of involvement for the athlete. ${ }^{12,13}$ For example, prior research shows that alcohol use is more prevalent among males that play hockey and women that play soccer ${ }^{14}$ among atheletes who play contact sports, ${ }^{12}$ and that team leaders have higher rates compared to other team members. ${ }^{15}$ Some researchers have used a social norms framework to explain high levels of binge drinking among college students. ${ }^{11}$ In addition, several researchers argue that athletes are a unique population and that the dual roles of student and athlete place them at increased risk for use. ${ }^{5,16,17}$ This research highlights the stress associated with maintaining a high level of athletic performance, 
difficulty balancing academic and athletic interests, concerns about professional careers, an increase risk for injuries, dealing with success and failures both on and off the field, and managing multiple interpersonal relationships.

More recently, research has begun to focus on the relationship between sports involvement and non-medical use of prescription drugs (NUPD), which is generally defined as use of prescription medications that have not been prescribed or the use of prescription medications solely for the feeling or experience caused by the drug. ${ }^{18}$ NUPD, particularly opioids, has become one of the most prevalent forms of substance use among adolescents and young adults. ${ }^{18,19}$ A few studies have shown that sports involvement is significantly associated with NUPD. ${ }^{13,20-24}$

A few studies have assessed the relationship between sports involvement and non-medical use of prescription opioids (NUPO). Cottler et al. interviewed former players in the National Football League and found that $71 \%$ of the players reported NUPO during their careers. This research also found that a history of injuries and concussions was significantly related to current NUPO. ${ }^{20}$ Using data from the Monitoring the Future Study, Veliz et al. found that sports involvement was associated with an increased risk for NUPO, especially among athletes involved in high contact sprts. ${ }^{23,24}$ However, analyzing data from the 2001 College Alcohol Study, Ford found that college students involved in athletics were at decreased risk for both NUPO and non-medical use of prescription tranquilizers compared to non-athletes. ${ }^{13}$ Additional research has also looked at the relationship between sports involvement and non-medical use of prescription stimulants. These studies have shown that both adolescent ${ }^{21}$ and college ${ }^{22}$ athletes were at decreased risk for stimulant misuse compared to non-athletes. This research also showed that a main motivation for non-medical use of prescription stimulants among athletes was to increase athletic performance. $^{21}$

What little research exists on sports involvement and NUPD seems to indicate that adolescents and young adults involved in sports are more likely to report NUPD. What is less clear is why this relationship exists. Some studies indicate that athletes are more likely to be prescribed drugs ${ }^{23}$ and separate research has shown that people who have been prescribed drugs are more likely to report NUPD. ${ }^{25,26}$ This research also shows that the relationship between sports involvement and NUPD is both gendered ${ }^{22,23}$ and based on the type of sport played. $^{22,24}$ These findings lead researchers to speculate that athletes involved in high contact sports, especially males, are more likely to suffer a physical injury and that the relationship between sports involvement and NUPD may be mediated by risk of injury.

To better help understand the relationship between sports participation and NUPO it is helpful to consider the concept of the sport ethic. ${ }^{27}$ The "sport ethic" is a set of values and norms that help to shape the identity and define group membership for "real" athletes. It essentially serves as a moral imperative for athletes, those who aspire to be athletes, and creates a set of social norms that must be followed. The sport ethic is comprised of four key components or values. First, an athlete must be dedicated to the game. To a real athlete, nothing is more important to them than the sport they play and this is often evidenced by the sacrifices athletes are willing to make to play their sport. Second, an athlete must always strive for distinction which is evidenced by their ability to win. In their quest to achieve perfection, athletes must push themselves to their physical and mental limits to become the best. Third, an athlete accepts the risk involved in sport, must not fear injury, and be able to compete while injured. A true athlete is fearless, both mentally and physically, and it is this courage that often elevates their status among fellow athletes. Finally, an athlete must believe that there are no obstacles that can stop them from pursuing their goals. In the mind of an athlete, there is no obstacle that cannot be overcome by dedication and effort. This sport ethic places the behavior of athletes into a specific context. While society at large may identify certain actions as deviant, athletes use the sport ethic as a way to justify or rationalize these behavior. For example, if an athlete believes that a certain drug will help them compete, then they may be inclined to use that drug even if it is illegal, as the values and norms associated with the sport ethic are central to his/her identity.

Building on the idea of a sport ethic, Hughes and Coakley's concept of positive deviance can offer a theoretical framework for the study of substance use among athletes. ${ }^{27}$ Traditionally, behavior was defined as deviant when it violated social norms and elicited a negative social reaction. ${ }^{28}$ Positive deviance, on the other hand, is generally defined as the over-conformity to social norms that generally receives a positive social reaction. ${ }^{28}$ Hughes and Coakley argue that it is the overconformity to the values and norms of the "sport ethic" that pushes athletes to use performance enhancing drugs. ${ }^{27}$ Similarly, the concept of positive deviance can explain why athletes are at an increased risk for NUPO. The "sport ethic" outlines that athletes should not allow injury or pain take them off the field of play and a number of studies have shown that injury and pain are normalized among athletes. ${ }^{29-31}$ Adherence to the "sport ethic" would push athletes, especially males, to mask their pain so that they continue to compete. The inability to compete would be a threat to their identity as a "real" athlete and also be viewed as letting down their teammates and coaches. Accordingly, using Hughes and Coakley's concept of positive deviance can help us understand higher rates of NUPO among certain segments of athletes. ${ }^{22,32}$

The current research continues the line of investigation that examines the relationship between sports involvement and NUPO. We extend the existing research by focusing on college students, while much of the existing research measures sports involvement during the high school years. In addition, there is a dearth of research that examines the connections between sex, sports participation, injury history, and NUPO. Exploring the interconnections between these multiple risk factors for NUPO should provide a better understanding of this serious public health issue. This is especially important given 
the gendered nature of the sports participation and substance use relationship. ${ }^{34,35}$ To that end, several hypotheses will be tested that specify the following: (1) college athletescompared to non-athletes; (2) injured athletes-compared to athletes with no injury, non-athletes with an injury, and nonathletes with no injury; (3) male athletes-compared to female athletes, male non-athletes, and female non-athletes; and (4) injured male athletes - compared to female athletes with an injury, male athletes with no injury, and female athletes with no injury will be at the greatest risk of NUPO.

\section{METHODS}

\section{Sample}

We obtained data on college students for the fall and spring semesters between 2008 and 2011 from the American College Health Association-National College Health Assessment (ACHA-NCHA II). The ACHA-NCHA has been conducted biannually since 2000 and has had 624 different U.S. postsecondary institutions administer the ACHA-NCHA to roughly one million college students. ${ }^{36}$ Although postsecondary institutions self-select to participate in the ACHA-NCHA, the data publically released to researchers only includes institutions that used random sampling techniques to collect survey data from potential respondents. The response rates for the ACHA-NCHA between the fall semesters of 2008 and 2011 were approximately $28 \%$. The response rate for the ACHANCHA is lower than other college surveys of substance use, ${ }^{37}$ but consistent with response rates from other webbased surveys using similar methods. ${ }^{38,39}$

The researchers for this study chose to begin with the fall 2008 ACHA-NCHA, as this was the first year that the survey included questions regarding collegiate athletic status. The sample for this study included 391 different U.S. postsecondary institutions that collected the ACHA-NCHA from 379,584 respondents during these three academic years (ie, fall 2008/ spring 2009, fall 2009/spring 2010, and fall 2010/spring $2011)$. Roughly $9 \%$ of the sample was removed $(35,051)$ due to excluding respondents 31 years of age or older, leaving a total sample size of 344,533 respondents between the ages of 18 and 30. Moreover, we also removed respondents with missing data on any of the variables used in the analyses (see Table 1). Removal of these missing data resulted in a final sample size of 320,412 respondents. Multiple imputation was used to assess whether the removal of the excluded respondents biased the findings from the sample with complete data. Results were comparable between the analyses that used multiple imputation and listwise deletion. Accordingly, the authors report the results from the analyses using listwise deletion.

\section{Measures}

To measure non-medical use of prescription opioids respondents were asked ... in the past 12 months, have you taken any of the following prescription drugs (pain killers such as OxyContin, Vicodin, or Codeine) that were not prescribed to you, coded $0=$ No, $1=$ Yes. The measure of sports involvement, also measured in the past 12 months, identified respondents who participated in organized college athletics at the varsity level, coded $0=$ No, $1=$ Yes. Varsity level athletes are those involved in sports teams that are controlled by the school's athletic department and do not include club and intramural sports. The NCHA II also included a number of items that focused on the physical health of the respondents, who were asked if they had been diagnosed or treated by a health professional for a list of several conditions over the past 12 months. These questions focused on health problems in general and not those specifically related to sports involvement. Our measure of injury was based on the following physical health problems: back pain; a broken bone, fracture, or sprain. Injury was coded 0 if a respondent reported none of these problems and 1 if a respondent reported any of these problems.

All analytic models included the following covariates: sex, age, race, sexual orientation, grade point average, greek affiliation, school type (ie, public versus private), region of the country, diagnosed/treated for depression in the past 12 months, past 30 day cigarette use, past two week binge drinking (ie, $5+$ drinks in one sitting), past 30 day marijuana use, and past year nonmedical use of prescription drugs other than opioids (ie, antidepressants, sedatives, and stimulants).

\section{Analytic Strategy}

Multiple logistic regression was used to examine the hypotheses outlined above. First, logistic regression models were estimated to assess whether injury during the past year, athletic status, and sex of respondent was associated with past year NUPO when controlling for several potentially confounding factors. Second, several additional logistic regression analyses were conducted to assess if male athletes (when compared to male non-athletes, female athletes, and female non-athletes), injured athletes (when compared to non-injured athletes, injured non-athletes, and non-injured non-athletes), and injured male athletes (when compared to non-injured male athletes, injured male non-athletes, noninjured male non-athletes, injured female athletes, noninjured female athletes, injured female non-athletes, and non-injured female non-athletes) had the highest risk of NUPO, when controlling for other potentially confounding factors.

STATA 14.0 was used to estimate the models outlined above (Version 14.0; StataCorp LP, College Station, Texas). All logistic regression models provide adjusted odds ratios (AOR) and $95 \%$ confidence intervals $(95 \% \mathrm{CI})$ while controlling for confounders. All analyses used robust standard errors to correct for the potential bias introduced through similar respondents being clustered within institutions (ie, 391 institutions that self-selected to participate in the ACHANCHA). 


\begin{tabular}{|c|c|c|c|}
\hline & \multicolumn{3}{|c|}{ Listwise deletion $n=320,412$} \\
\hline & $\%$ & SE & $\%$ Item missing \\
\hline NUPO (past 12 months) & 8.3 & 0.002 & 0.60 \\
\hline Varsity athlete & 8.0 & 0.004 & 2.00 \\
\hline Injury (past 12 months) & 17.4 & 0.003 & 0.60 \\
\hline Female & 65.6 & 0.005 & 0.80 \\
\hline Age 18 to 20 & 53.3 & 0.017 & 0 \\
\hline Age 21 to 23 & 31.1 & 0.007 & \\
\hline Age 24 to 26 & 9.2 & 0.009 & \\
\hline Age 27 to 30 & 6.4 & 0.008 & \\
\hline Non-white & 26.0 & 0.012 & 0.20 \\
\hline Sexual minority (gay, lesbian, bi-sexual) & 7.1 & 0.002 & 1.10 \\
\hline GPA (A) & 37.8 & 0.011 & 1.20 \\
\hline GPA (B) & 47.4 & 0.007 & \\
\hline GPA $(\mathrm{C})$ & 11.5 & 0.006 & \\
\hline GPA (D/F) & 0.7 & 0.000 & \\
\hline GPA (Not applicable) & 2.6 & 0.003 & \\
\hline Greek affiliated & 9.7 & 0.005 & 1.40 \\
\hline Attends a private University & 36.6 & 0.040 & 0.00 \\
\hline School region (Northeast) & 28.4 & 0.043 & 0.00 \\
\hline School region (Midwest) & 17.3 & 0.023 & \\
\hline School region (South) & 25.1 & 0.031 & \\
\hline School region (West) & 25.3 & 0.030 & \\
\hline School region (outside US) & 3.8 & 0.013 & \\
\hline Diagnosed/treated for depression (past 12 months) & 9.4 & 0.002 & 0.90 \\
\hline Smoked cigarettes (past 30 days) & 15.5 & 0.003 & 0.40 \\
\hline Engaged in binge drinking (past 2 weeks) & 35.5 & 0.006 & 0.40 \\
\hline Smoked marijuana (past 30 days) & 16.0 & 0.004 & 0.60 \\
\hline Other NUPD (past 12 months) & 10.0 & 0.003 & 0.30 \\
\hline
\end{tabular}

GPA, grade point average; NUPO, nonmedical use of prescription opioids; NUPD, Nonmedical use of prescription drugs (other than opioids).

\section{RESULTS}

Descriptive statistics for all measures are shown in Table 1. Roughly $8.0 \%$ of the sample indicated being a varsity athlete during the past year. Among all of the respondents, $17.4 \%$ indicated an injury during the past year and $8.3 \%$ indicated NUPO during the past year.

\section{Individual Effects of Injury During the Past Year, Athletic Status, and Sex}

Table 2 shows the overall results of the association between participation in varsity athletics, NUPO, and injury during the past year. Participation in varsity athletics was associated with both a greater odds of NUPO (AOR $=1.26[95 \% \mathrm{CI}$ : $1.94-1.33])$ and injury (AOR $=2.19$ [95\%CI: 2.11-2.28]) when compared to non-athletes when controlling for covariates. Moreover, the odds of NUPO $(\mathrm{AOR}=1.87$ [95\%CI: $1.80-1.93]$ ) and having sustained an injury (AOR $=1.85[95 \%$ CI: 1.79-1.92]) during the past year is roughly two times higher when compared to respondents who either did not engage in NUPO or indicated not sustaining an injury during the past year.

\section{Combined Effects of Injury During the Past Year, Athlete Status, and Sex}

Table 3 provides the unadjusted and adjusted odds ratios assessing the association of NUPO by sex, athletic status, and injury during the past year. Models 3 and 4 show that male athletes have the highest odds of NUPO when compared to female athletes, male non-athletes, and 


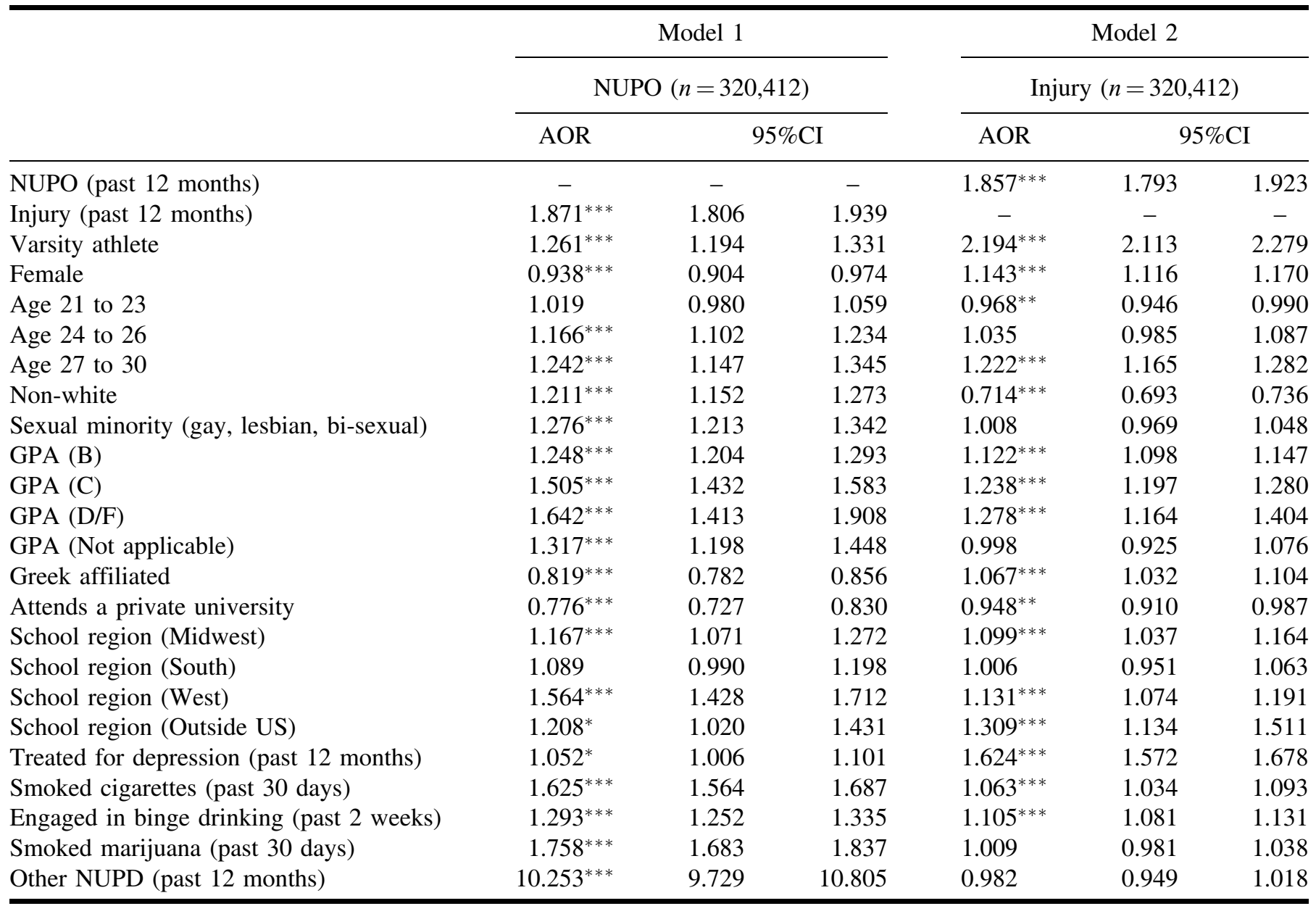

AOR, adjusted odds ratio; 95\%CI, confidence interval GPA, grade point average; NUPO, nonmedical use of prescription opioids; NUPD, Nonmedical use of prescription drugs (other than opioids). $p<.05^{*}, p<.01^{* *}, p<.001^{* * *}$.

female non-athletes. Models 5 and 6 show that injured athletes have the highest odds of NUPO when compared to athletes who were not injured, injured non-athletes, and non-athletes who were not injured (note that the injured non-athletes and injured athletes had similar odds of NUPO in the model without control variables). Finally, models 7 and 8 show that injured male athletes have the highest odds of NUPO when compared to injured female athletes, injured male non-athletes, injured female nonathletes, male athletes who were not injured, female athletes who were not injured, male non-athletes who were not injured, and female non-athletes who were not injured.

\section{DISCUSSION}

The NUPD, specifically opioid analgesics, has become a major public health issue in the United States. This makes research identifying populations at increased risk for NUPO of particular importance. We extend the research in this area by examining the relationship between college athletic involvement and NUPO. In addition, we are the first to examine how injury status impacts this relationship.

Findings show that roughly $8 \%$ of the students in the NCHA report NUPO in the past year. This prevalence rate is higher than data from the Monitoring the Future study (6.2\%) that looked at drug use among college students one to 4 years beyond high school during the same period. ${ }^{18}$ Additionally, about $8 \%$ of the sample reported being a varsity athletes, $17 \%$ reported an injury (ie, back pain, broken bone, or sprain), and $66 \%$ were females. The $8 \%$ of the sample that identified as a varsity athlete in the NCHA is comparable to data from the 2011-2012 National Survey of Student Engagement, a national study of first-year and senior students that indicates about $7.5 \%$ of U.S. college students are student-athletes. ${ }^{40}$

The goal of the current research was to examine the relationship between sports involvement and NUPO among college students and determine if this relationship varied based on injury status and sex of the respondent. Our analyses confirmed several hypotheses, we found that athletes, injured athletes, male athletes, and injured male athletes were at the 
TABLE 3. Examining the association between sport participation, NUPO, and Injury during the past year

\begin{tabular}{|c|c|c|c|c|c|c|c|}
\hline & \multirow[b]{3}{*}{$\%$} & \multicolumn{3}{|c|}{ NUPO $(n=320,412)$} & \multicolumn{3}{|c|}{ NUPO $(n=320,412)$} \\
\hline & & \multicolumn{3}{|l|}{ Model 3} & \multicolumn{3}{|l|}{ Model 4} \\
\hline & & OR & \multicolumn{2}{|c|}{$95 \% \mathrm{CI}$} & AOR & \multicolumn{2}{|c|}{$95 \% \mathrm{CI}$} \\
\hline \multicolumn{8}{|l|}{ Gender and athletic status } \\
\hline Male athlete & 11.5 & - & - & - & - & - & - \\
\hline Female athlete & 7.4 & $0.617^{* * *}$ & 0.562 & 0.678 & $0.753^{* * *}$ & 0.684 & 0.828 \\
\hline Male non-athlete & 9.2 & $0.782^{* * *}$ & 0.728 & 0.839 & $0.696^{* * *}$ & 0.644 & 0.752 \\
\hline Female Non-athlete & 7.7 & $0.642^{* * *}$ & 0.599 & 0.690 & $0.668^{* * *}$ & 0.618 & 0.722 \\
\hline & & Model 5 & & & Model 6 & & \\
\hline \multicolumn{8}{|l|}{ Injury status and athletic status } \\
\hline Athlete (injured) & 13.5 & - & - & - & - & - & - \\
\hline Athlete (not injured) & 7.2 & $0.497^{* * *}$ & 0.457 & 0.541 & $0.527^{* * *}$ & 0.479 & 0.580 \\
\hline Non-athlete (injured) & 13.6 & 1.011 & 0.936 & 1.092 & $0.786^{* * *}$ & 0.721 & 0.857 \\
\hline \multirow[t]{2}{*}{ Non-athlete (not injured) } & 7.1 & $0.491^{* * *}$ & 0.456 & 0.529 & $0.421^{* * *}$ & 0.388 & 0.457 \\
\hline & & Model 7 & & & Model 8 & & \\
\hline \multicolumn{8}{|c|}{ Gender, athletic status, and injury status } \\
\hline Male athlete (injury) & 17.9 & - & - & - & - & - & - \\
\hline Female athlete (injury) & 10.6 & $0.542^{* * *}$ & 0.470 & 0.624 & $0.672^{* * *}$ & 0.576 & 0.785 \\
\hline Male athlete (no injury) & 8.9 & $0.445^{* * *}$ & 0.395 & 0.500 & $0.477^{* * *}$ & 0.418 & 0.543 \\
\hline Female athlete (no injury) & 6.0 & $0.294^{* * *}$ & 0.260 & 0.333 & $0.387^{* * *}$ & 0.340 & 0.440 \\
\hline Male non-athlete (injury) & 16.1 & $0.879^{*}$ & 0.791 & 0.977 & $0.673^{* * *}$ & 0.598 & 0.758 \\
\hline Female non-athlete (injury) & 12.5 & $0.653^{* * *}$ & 0.591 & 0.721 & $0.609^{* * *}$ & 0.543 & 0.684 \\
\hline Male non-athlete (no injury) & 7.9 & $0.394^{* * *}$ & 0.358 & 0.435 & $0.343^{* * *}$ & 0.308 & 0.382 \\
\hline Female non-athlete (no injury) & 6.7 & $0.328^{* * *}$ & 0.298 & 0.362 & $0.336^{* * *}$ & 0.301 & 0.374 \\
\hline
\end{tabular}

AOR, adjusted odds ratio; 95\% CI, confidence interval; GPA, grade point average; NUPO, nonmedical use of prescription opioids; NUPD, Nonmedical use of prescription drugs. Models 4,6 , and 8 control the covariates outlined in table 2 (model 1).

$p<.05^{*}, p<.01^{* *}, p<.001^{* * *}$.

greatest risk of NUPO. For instance, roughly $17.9 \%$ (see Table 3 ) of injured male athletes indicated NUPO, this is more than two times higher than the average rate found within the college population used for this study (ie, $8.3 \%$ of college students indicate NUPO). In addition, the prevalence of NUPO among injured male athletes is considerably higher than male college students $(7.5 \%)$ and their male non-college peers (9.6\%) found in other national studies. ${ }^{19}$

In the logistic regression models that examined our variables of interest separately, shown in Table 2, we found that respondent sex, athletic status, and injury status were all significantly associated with NUPO. These findings are supported by previous research. A number of studies show that males are more likely to report NUPO compared to females. ${ }^{19,25,26}$ This research also adds to the growing body of literature that identifies sports involvement as a correlate of NUPO ${ }^{33,34}$ While not surprising, the current research is one of the first to show that college students who reported an injury were more likely to report NUPO.

By looking at the combined effects of respondent sex, athletic status and injury status, this research makes a major contribution to our understanding of NUPO. In looking at sex and athletic status we found that male athletes were most likely to report NUPO. Our analysis that combined injury and athletic status showed that athletes with histories of injuries were most likely to report NUPO. Finally, we assessed the combined effects of respondent sex, athletic status and injury while controlling for relevant covariates. In this analysis we found that male athletes with injuries were more likely to report NUPO.

To place this important finding in context we rely on the concepts of the "sport ethic" and positive deviance that were outlined by Hughes and Coakley. ${ }^{27}$ As stated previously, positive deviance is broadly understood as the overconformity to social norms that results in a positive social reaction. Hughes and Coakley showed the importance of immersing oneself into the identity of a real athlete. The values and norms that are central to the sport ethic play an important role in NUPO among athletes. Central to the identity of a real athlete is the notion that one must pose the proper attitude. Competitive athletes reveal that attitude by making physical and emotional sacrifices and showing that nothing comes between an athlete and his or her sport. In addition, an athlete accepts the risks involved in training for and playing their 
sport, they understand that pain, or injury, is a certainty. This translates into the moral imperative that athletes must push through injury as a way to show dedication to their sport, as well as their coaches and teammates. The NUPO is almost a certainty among athletes, in order to be true to themselves as well as their teammates, and coaches a real athlete must do whatever it takes to stay on the field and compete, especially at the varsity level.

A few limitations are worth noting. The current study relies on cross-sectional data, so examining the temporal associations between athlete status, injury, and NUPO is not possible. The current research also does not distinguish the type of sport played, which is important given the link between participation in high contact sports and nonmedical prescription drug use. $^{12,33,34}$ Third, the measure of NUPO only includes the use of prescription medications that are not prescribed and does not include the misuse of medications that are prescribed. Finally, the current findings are not generalizable to all U.S. college students, as the NCHA sample is not representative and also had a low response rate. However, the NCHA data is comparable to other national studies of college students, in regard to both athletic involvement (National Survey of Student Engagement) and substance use (Monitoring the Future). Despite these limitation, this study makes a novel contribution by building on a small handful of studies that have identified sports participation as a risk factor for NUPO among adolescents.

The current research analyzed data from a large national sample of college students to assess the relationship between sports involvement and NUPO. While prior research showed that gender played an important role in this relationship, the current research found that injury status was also an important consideration. Respondents who were injured, regardless of their gender or athletic status, consistently reported the highest prevalence of NUPO. Given the devastating toll of NUPO in the United States, research identifying which factors and combinations of factors are related to use are important. In order to be effective, prevention, and intervention programs must know which groups are most likely to be at risk for NUPO.

\section{Declaration of Interests}

The authors report no conflicts of interest. The authors alone are responsible for the content and writing of this paper.

\section{REFERENCES}

1. National Collegiate Athletic Association. NCAA recruiting facts. www. ncaa.org. Accessed July 19, 2017.

2. Miller KE, Melnick MJ, Barnes GM, et al. Athletic involvement and adolescent delinquency. J Youth Adolesc. 2007;36:711-723.

3. Spruit A, van Vugt E, van der Put C, et al. Sports participation and juvenile delinquency: A meta-analytic review. $J$ Youth Adolesc. 2016;45:655-671.

4. Veliz P, Shakib S. Interscholastic sports participation and school based delinquency: Does participation in sport foster a positive high school environment. Sociol Spectrum. 2012;32:558-580.
5. Buckman JF, Yusko DA, Farris SG, et al. Risk of marijuana use in male and female college student athletes and nonathletes. J Study Alcohol Drugs. 2011;72:586-591.

6. Kwan M, Bobko S, Faulkner G, et al. Sport participation and alcohol and illicit drug use in adolescents and young adults: A systematic review of longitudinal studies. Addict Behav. 2014;39:497-506.

7. Eime RM, Young JA, Harvey JT, et al. A systematic review of the psychological and social benefits of participation in sport for children and adolescents: Informing development of a conceptual model of health through sport. Int J Behav Nutr Phys Act. 2013;10:2-21.

8. Janssen I, LeBlanc AG. Systematic review of the health benefits of physical activity and fitness in school-aged children and youth. Int $J$ Behav Nutr Phys Act. 2010;7:1-16.

9. Veliz P, Shakib S. Gender, academics, and interscholastic sports participation at the school level: A gender-specific analysis of the relationship between interscholastic sports participation and AP enrollment. Sociol Focus. 2014;47:101-120.

10. Hirschi T. Causes of delinquency. Berkeley: University of California Press; 1969

11. Ford JA. Alcohol use among college students: A comparison of athletes and non-athletes. Subst Use Misuse. 2007;42:1367-1377.

12. Veliz P, Boyd CJ, McCabe SE. Competitive sport involvement and substance use among adolescents: A nationwide study. Subst Use Misuse. 2015;50:156-165.

13. Ford JA. Nonmedical prescription drug use among college students: A comparison between athletes and nonathletes. $J$ Am Coll Health. 2008;57:211-219.

14. Ford JA. Substance use among college athletes: A comparison based on sport/team affiliation. J Am Coll Health. 2007;55:367-373.

15. Leichliter JA, Meilman PW, Presley CA, et al. Alcohol use and related consequences among students with varying levels of involvement in college athletics. J Am Coll Health. 1998;46:257-262.

16. Martens MP, Dams-O'Connor K. Beck NC A systematic review of college student-athlete drinking: Prevalence rates, sport-related factors, and interventions. J Subst Abuse Treat. 2006;31:305-316.

17. Yusko DA, Buckman JF, White HR, et al. Risk for excessive alcohol use and drinking-related problems in college student athletes. Addict Behav. 2008;33:1546-1556.

18. Center for Behavioral Health Statistics and Quality. 2014 National survey on drug use and health: Detailed tables. Substance Abuse and Mental Health Services Administration, Rockville, MD; 2015.

19. Johnston LD, O'Malley PM, Bachman JG, et al. Monitoring the future national survey results on drug use, 1975-2011: Volume II, College students and adults ages 19-50. Ann Arbor: Institute for Social Research, The University of Michigan; 2012.

20. Cottler LB, Abdallah AB, Cummings SM, et al. Injury, pain, and prescription opioid use among former National Football League (NFL) players. Drug Alcohol Depend. 2011;116:188-194.

21. Gallucci AR, Martin RJ. Misuse of prescription stimulant medication in a sample of college students: Examining differences between varsity athletes and non-athletes. Addict Behav. 2015;51:44-50.

22. Veliz P, Boyd C, McCabe SE. Adolescent athletic participation and nonmedical Adderall use: An exploratory analysis of a performanceenhancing drug. J Stud Alcohol Drugs. 2013;74:714-713.

23. Veliz P, Epstein-Ngo QM, Meier E, et al. Painfully obvious: A longitudinal examination of medical use and misuse of opioid medication among adolescent sports participants. J Adolesc Health. 2014;54: 333-340.

24. Veliz P, Boyd CJ, McCabe SE. Nonmedical use of prescription opioids and heroin use among adolescents involved in competitive sports. $J$ Adolesc Health. 2017;60:346-349.

25. McCabe SE, West BT, Teter CJ, et al. Trends in medical use, diversion, and nonmedical use of prescription medications among college students from 2003 to 2013: Connecting the dots. Addict Behav. 2014;39: $1176-1182$.

26. McCabe SE, Teter CJ, Boyd CJ. Medical use, illicit use, and diversion of abusable prescription drugs. $J$ Am Coll Health. 2006;54:269-278. 
27. Hughes R, Coakley J. Positive deviance among athletes: The implications of overconformity to the sport ethic. Sociol Sport J. 1994;1:307-325.

28. Heckert A, Heckert D. A new typology of deviance: Integrating normative and reactivist definitions of deviance. Deviant Behav. 2002;23:449-479.

29. Delaney JS, Lamfookon C, Bloom GA, et al. Why university athletes choose not to reveal their concussion symptoms during a practice or game. Clin J Sport Med. 2015;25:113-125.

30. Kroshus E, Garnett B, Hawrilenko M, et al. Concussion under-reporting and pressure from coaches, teammates, fans, and parents. Soc Sci Med. 2015;134:66-75.

31. Meehan WP, III, Mannix RC, O'Brien MJ, et al. The prevalence of undiagnosed concussions in athletes. Clin J Sport Med. 2013;23: 339-342.

32. Denham B. High school sports participation and substance use: Differences by sport, race and gender. $J$ Child Adoles Subst. 2014;23: 145-154.

33. Veliz P, Boyd C, McCabe SE. Playing through pain: Sports participation and nonmedical use of opioid medications among adolescents. $A m J$ Public Health. 2013;103:e28-e30.
34. Veliz P, Epstein-Ngo QM, Austic E, et al. Opioid use among interscholastic sports participants: An exploratory study from a sample of college students. Res Q Exerc Sport. 2015;86:205-211.

35. Veliz P, Epstein-Ngo Q, Zdroik J, et al. Substance use among sexual minority collegiate athletes: A national study: corrigendum. Subst Use Misuse. 2016;51:517-532.

36. America College Health Association. ACHA-NCHA data. Retrieved from http://www.acha-ncha.org/pubs_rpts.html.

37. McCabe SE, Boyd CJ, Couper MP, et al. Mode effects for collecting alcohol and other drug use data: web and U.S. mail. J Stud Alcohol. 2002;63:755-761.

38. Cook C, Heath F, Thompson RL. A meta-analysis of response rates in web-or internet-based surveys. Educ Psychol Meas. 2000;60: 821-835.

39. Shih TH, Fan X. Comparing response rates from web and mail surveys: A meta-analysis. Field Method. 2008;20:249-271.

40. National Survey of Student Engagegment. Retrived from http://nsse. indiana.edu/. 